Supplement of Geosci. Model Dev., 14, 1949-1985, 2021

https://doi.org/10.5194/gmd-14-1949-2021-supplement

(C) Author(s) 2021. CC BY 4.0 License.

(c) (i)

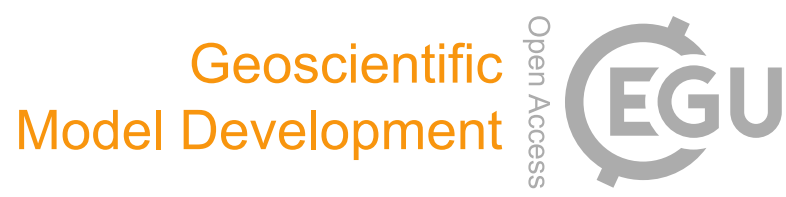

Supplement of

\title{
SPEAD 1.0 - Simulating Plankton Evolution with Adaptive Dynamics in a two-trait continuous fitness landscape applied to the Sargasso Sea
}

\section{Guillaume Le Gland et al.}

Correspondence to: Guillaume Le Gland (legland@icm.csic.es)

The copyright of individual parts of the supplement might differ from the article licence. 


\section{Supporting Online Material}

\section{SPEAD 1.0 bulk properties at different mutation rates and bulk properties in a model without trait diversity}

In this supplementary material, we show the distributions in time and depth of four non-trait SPEAD model outputs ("bulk properties"): primary production, chlorophyll concentration, dissolved inorganic nitrogen concentration and particulate organic nitrogen concentration. In Fig. S1, we compare the bulk properties of three simulations with different values of the mutation rates: $\nu_{x}=0.1, \nu_{x}=0.001$ and $\nu_{x}=10^{-5}$. The ratio of the two mutation rates, $\frac{\nu_{y}}{\nu_{x}}$ is always equal to $10^{\circ} C^{2}$. In Fig. S2, the bulk properties of models based on SPEAD parameters but without trait diversity are shown. There are two ways of removing a trait from a trait-based model: giving it a fixed value or assuming that it is always optimal. We added a third simulation, because models without traits (NPZD) generally handle optimal temperatures and nutrient niches in opposite ways. The temperature niches of plankton species is neglected, implicitly assuming that they are always adapted to their environment, with an optimal temperature equal to the environment temperature $\left(T_{o p t}=T\right)$. By contrast, the half-saturation, and then the nutrient niche, is set to a constant value. To represent the full possibilities of NPZD models, we made three 0-trait simulations: one with both traits set to constant values, one with a constant half-saturation and an optimal temperature equal to the environment temperature, and one with both traits equal to their environmental drivers. When constant values are used, we choose the mean trait values after convergence of the control simulation without trait diffusion: $K_{n}=0.96$ mmolN m${ }^{-3}$ and $T_{o p t}=23.4^{\circ} \mathrm{C}$.

The total primary production over a year varies between $130.8 \mathrm{gC} \mathrm{m}^{-2} \mathrm{~d}^{-1}$ in the SPEAD simulation with the highest mutation rates $\left(\nu_{x}=0.1\right.$ and $\left.\nu_{y}=1.0{ }^{\circ} \mathrm{C}^{2}\right)$ and $147.5 \mathrm{gC} \mathrm{m}^{-2} \mathrm{~d}^{-1}$ in the 0-trait simulation where phytoplankton is always optimally adapted to its environment. The distribution pattern is even less variable as it is largely constrained by the vertical mixing and the total nitrogen content. The only noticeable difference in pattern is that primary production shifts marginally towards the surface in summer when total production is low, as more nutrients can get to the surface before being consumed, or when adaptation to the high warm nutrient-poor summer surface waters is fast (high mutation rates) or instantaneous $\left(K_{n}=N\right.$ and $\left.T_{o p t}=T\right)$. 

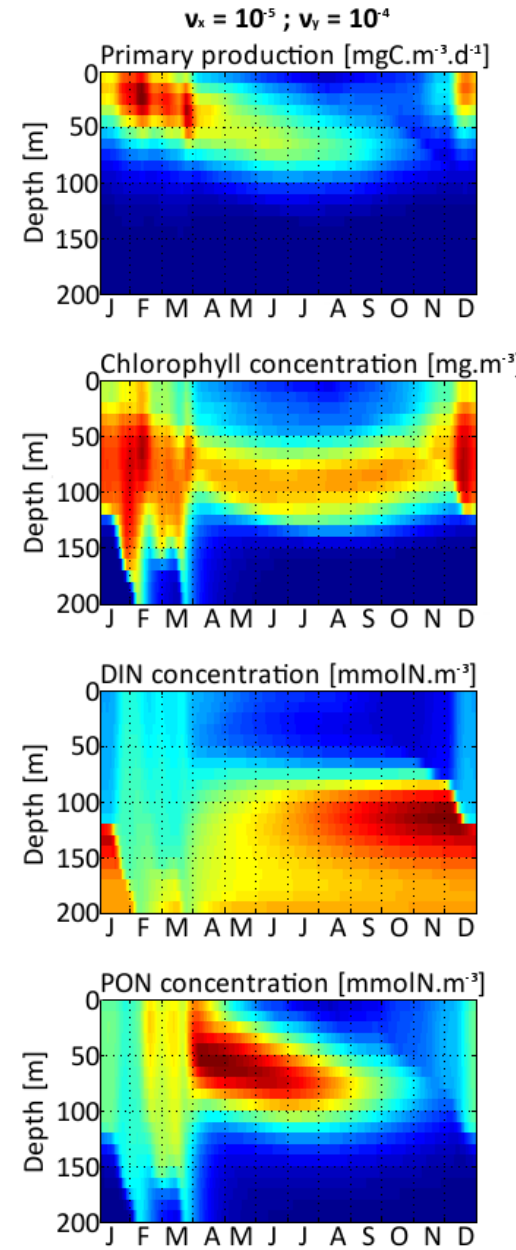

$v_{\mathrm{x}}=0.001 ; v_{\mathrm{y}}=0.01$
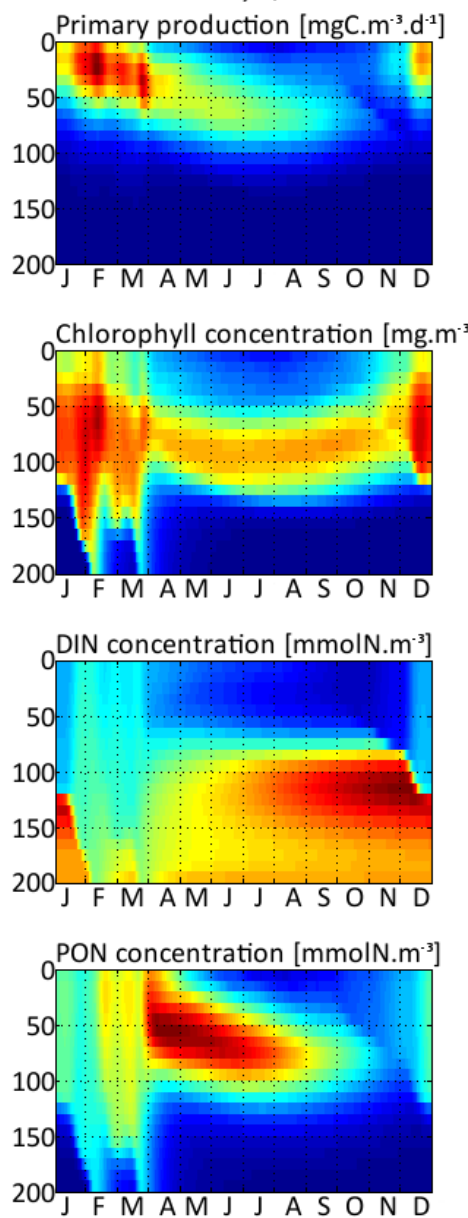

$\mathbf{v}_{\mathrm{x}}=\mathbf{0 . 1} ; \mathbf{v}_{\mathrm{y}}=\mathbf{1 . 0}$
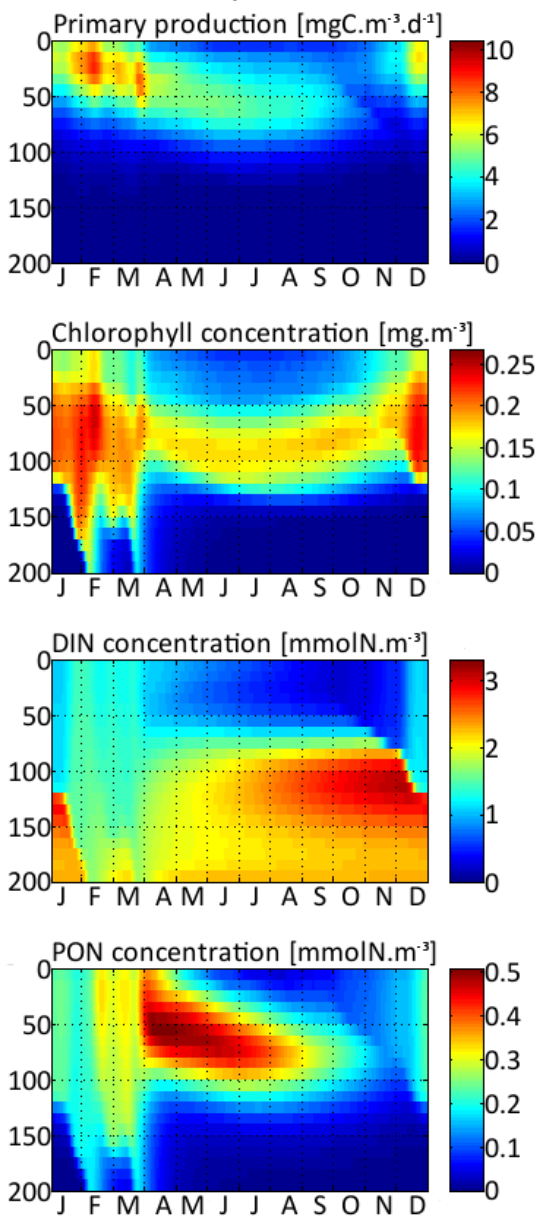

Figure S1. SPEAD 1.0 bulk properties outputs of three simulations with different mutation rates 

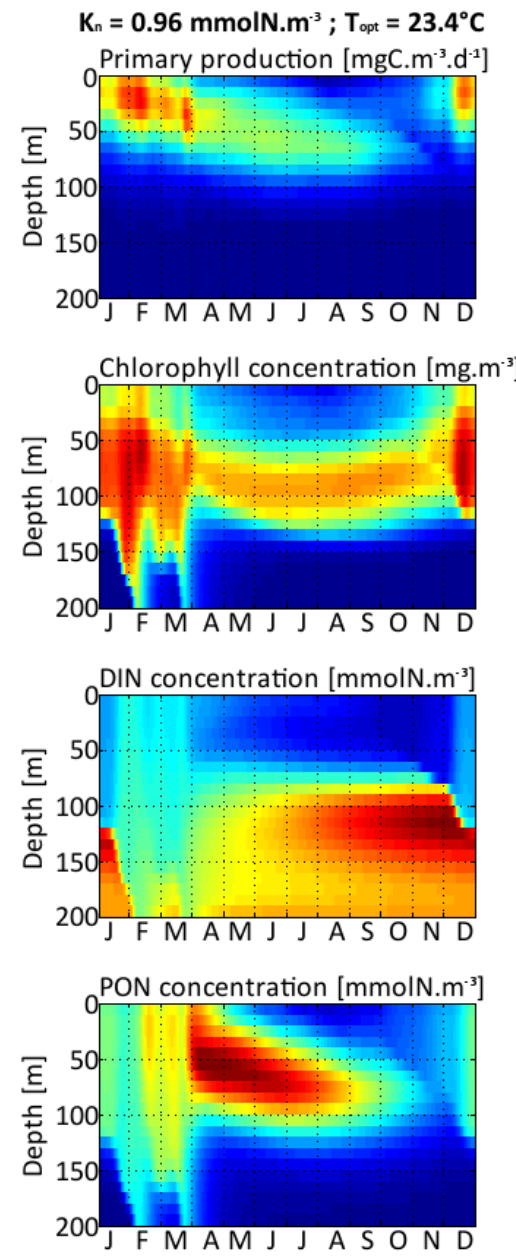
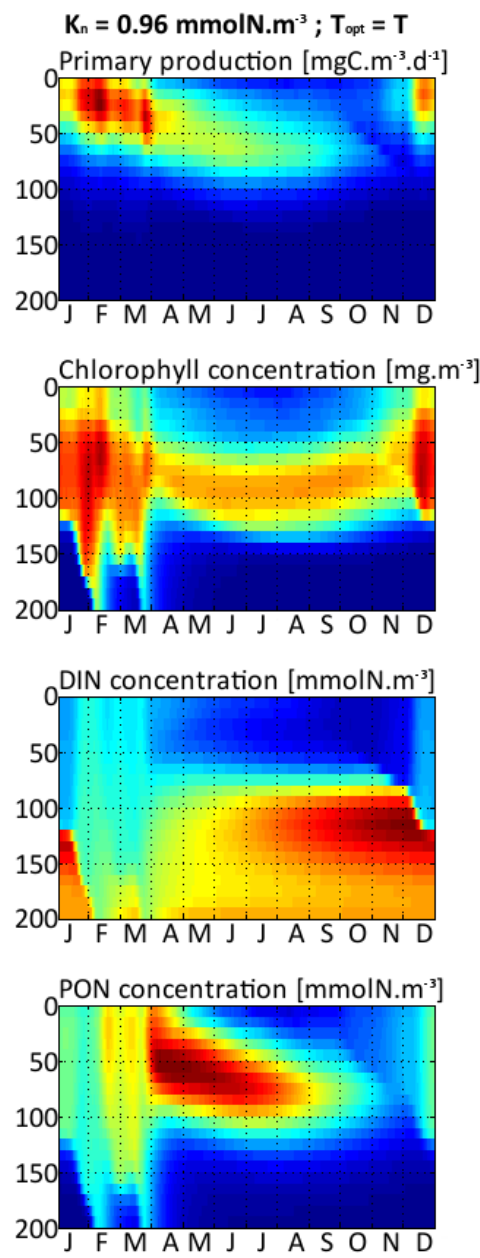

$K_{n}=\mathbf{N} ; T_{\text {opt }}=\mathbf{T}$
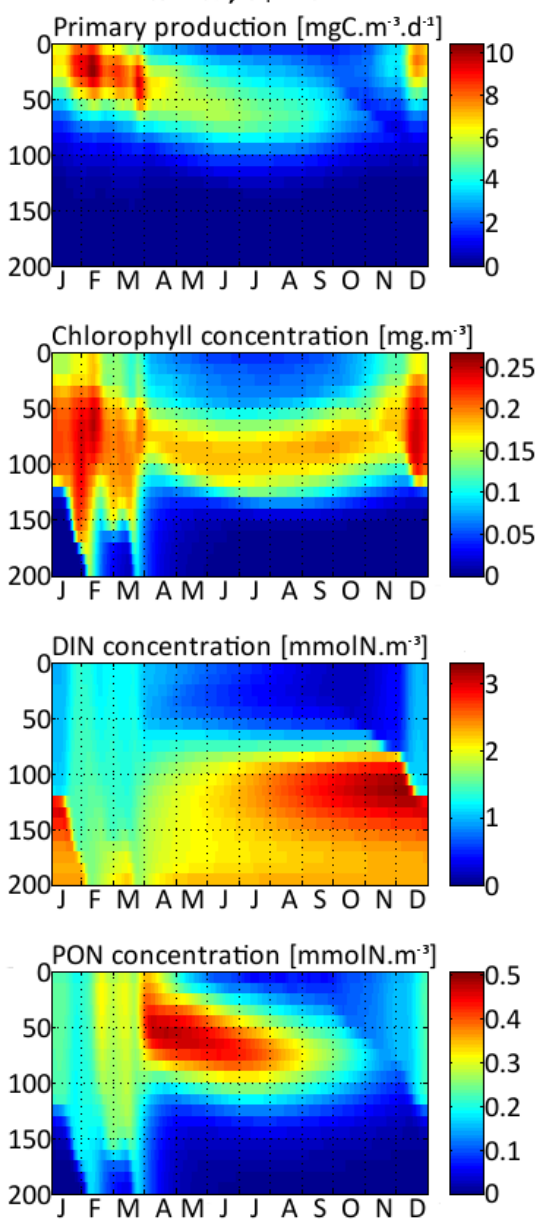

Figure S2. Bulk properties outputs of three simulations without trait diversity 